\title{
Role of inosine triphosphate pyrophosphatase gene variant on fever incidence during zidovudine antiretroviral therapy
}

\author{
A.V.C. Coelho ${ }^{1}$, S.P.S. Silva ${ }^{2}$, L. Zandonà ${ }^{3}$, G. Stocco ${ }^{3}$, G. Decorti ${ }^{3}$ and \\ S. Crovella ${ }^{1,4}$ \\ ${ }^{1}$ Departamento de Genética, Universidade Federal de Pernambuco Federal de \\ Pernambuco, Recife, PE, Brasil \\ ${ }^{2}$ Programa de Pós-Graduação em Inovação Terapêutica, Universidade Federal \\ de Pernambuco Federal de Pernambuco, Recife, PE, Brasil \\ ${ }^{3}$ Department of Life Sciences, University of Trieste, Trieste, Italy \\ ${ }^{4}$ Institute for Maternal and Child Health, Scientific Institute for Research, \\ Hospitalization and Care Burlo Garofolo, Trieste, Italy \\ Corresponding author: A.V.C. Coelho \\ E-mail: antonio.victor@ufpe.br/avccbio@gmail.com
}

Genet. Mol. Res. 16 (1): gmr16019373

Received September 22, 2016

Accepted November 18, 2016

Published January 23, 2017

DOI http://dx.doi.org/10.4238/gmr16019373

Copyright $(2017$ The Authors. This is an open-access article distributed under the terms of the Creative Commons Attribution ShareAlike (CC BY-SA) 4.0 License.

\begin{abstract}
Zidovudine, the antiretroviral drug used to treat HIV infection, commonly causes adverse effects, such as systemic fever and gastrointestinal alterations. In the present study, the potential role of inosine triphosphate pyrophosphatase (ITPA) gene variant on the incidence of adverse events during antiretroviral therapy (ART) of HIV with zidovudine was discussed. Individuals from Northeastern Brazil $(\mathrm{N}=204)$ receiving treatment for HIV-1 infection were recruited. Zidovudine-related adverse effects developed during the treatment were registered. The rs 1127354 polymorphism in the ITPA gene was
\end{abstract}


genotyped using real-time PCR to assess whether this single nucleotide polymorphism was associated with the occurrence of zidovudinerelated adverse effects. We observed a significant association between the ITPA variant genotype and the reported systemic fever (odds ratio $=7.17,95 \%$ confidence interval $=1.19-43.15 ; \mathrm{P}=0.032$ ). Zidovudine use could indirectly lead to an increase in the levels of inosine monophosphate in an antimetabolite-like manner, which is converted to inosine triphosphate (ITP). The rs1127354 variant caused a decrease in ITPA activity, thereby leading to ITP accumulation. This in turn resulted in cytotoxicity, which was manifested by neutropenia and fever. Therefore, we hypothesized a pharmacogenetic model involving the ITPA variant genotype in multifactorial components that act together to determine the onset of zidovudine-related adverse effects.

Key words: Antiretroviral; Adverse effect; AZT; ITPA

\section{INTRODUCTION}

The introduction of antiretroviral therapy (ART) in clinical practice significantly reduced the number of deaths due to human immunodeficiency virus type 1 (HIV-1) infection, which is the etiological agent of acquired immunodeficiency syndrome (AIDS). Current ART regimens consist of a combination of three antiretroviral drugs that target HIV-1 proteins, hampering the viral life-cycle completion (Cressey Lallemant, 2007). Azidothymidine (AZT), also known as zidovudine, was the first antiretroviral drug developed in the early years of the HIV-1 pandemics. AZT is a nucleoside analog reverse transcriptase inhibitor (NRTI), a class of molecules that blocks the synthesis of viral genetic material by inhibiting the DNA chain growth (Alves et al., 2012). AZT is still commonly used in first-line ART regimens in Brazil, as it is a relatively cheap and effective drug directly produced in Brazil. It is used in combination with another NRTI (the two NRTIs being the "backbone" of the ART regimens) and a third drug, such as a protease inhibitor (Ministério da Saúde, 2010).

ART is a lifelong commitment; therefore, it is sometimes associated with adverse drug reactions, which can be mild and temporary or very severe and life threatening. NRTIs may cause metabolic defects, such as dyslipidemia and lipodystrophy (Montessori et al., 2004). Some reports showed that AZT use is associated with systemic (such as fever) and gastrointestinal adverse effects (Jacobson et al., 1989; Vella et al., 1994).

Since AZT is a nucleoside analog, we hypothesized that it may interfere with the intracellular nucleoside/nucleotide biosynthesis pathways, similar to the mode of action of antimetabolite drugs, such as mercaptopurine and methotrexate, which interfere with purine metabolism (Marinaki et al., 2004).

Studies on the pharmacogenetics of nucleoside purine analogs (Mira et al., 2007; Fellay et al., 2010; Stocco et al., 2010) led to the hypothesis that inosine triphosphate pyrophosphatase (ITPA) could play an indirect role on AZT metabolism, possibly influencing the occurrence of adverse effects related to the drug.

ITPA is a housekeeping enzyme that dephosphorylates inosine triphosphate (ITP) and deoxy-ITP, converting them to monophosphate forms. This may be related to the protection

Genetics and Molecular Research 16 (1): gmr16019373 
of genome integrity, because the incorporation of inosine during nucleic acid synthesis may cause errors (von Ahsen et al., 2008).

A relatively common missense variant of the ITPA gene (ITPA), a single nucleotide polymorphism (SNP), which was identified as rs1127354 (94 C>A, Pro32Thr), is known to abolish the gene function. This missense SNP in heterozygotes was associated with the reduction in erythrocyte enzyme activity to approximately $25 \%$, while no enzyme activity was detected in A/A homozygotes (Maeda et al., 2005). This trait is benign, but has already been described as a risk factor for the occurrence of adverse effects during antimetabolite therapy (Marinaki et al., 2004).

The discovery of novel genetic markers associated with ART response together with other markers associated with immune response against HIV-1 infection (Samie et al., 2014; Said et al., 2016) helped in the optimization of current regimens and improvement of the quality of life in patients sustaining lifelong ART treatment. In this study, we evaluated whether the ITPA rs 1127354 polymorphism was associated with the occurrence of adverse effects of ART regimens containing AZT in HIV-1-positive patients from Northeast Brazil.

\section{MATERIAL AND METHODS}

We enrolled 204 patients from the metropolitan region of Recife (Northeast Brazil), at Instituto de Medicina Integral Professor Fernando Figueira (IMIP) for a genetic association, retrospective case-control study between May 2011 and August 2012. For inclusion in the study, each patient had to be between 18 and 50 years of age on the ART start date. In addition, patients should have been receiving ART (AZT-containing regimens) for at least 1 year with good treatment compliance, had no history of illegal drug abuse, and had no chronic diseases other than HIV-1 infection [no human T-lymphotropic virus type 1, hepatitis B or hepatitis $\mathrm{C}$ co-infections or autoimmune diseases, such as diabetes or systemic lupus erythematosus]. Each patient provided written consent for participation in the study and for the collection of blood samples for posterior genomic DNA extraction. They were invited and interviewed by the physicians/researchers. The IMIP Research Ethics Committee approved the study (protocol No. 2273-11).

Each patient answered a questionnaire, which was used to record the gender, age (in years) and body mass (in $\mathrm{kg}$ ) on the ART start date. In addition, the therapy adherence status [indirectly measured through medication possession ratio of the first year of the therapy as proposed by Fairman and Matheral (2000)], and self-reported race: as "white", "black" and "pardo" (multiracial) following (Coelho et al., 2015) the stratification rationale were also recorded. The outcome was the occurrence of any adverse effect ascribed to the use of AZT by the patient's physician. The patients received standard AZT + lamivudine (3TC) regimens $(300+150 \mathrm{mg}$ combination pill, twice daily).

The ITPA rs1127354 polymorphism was genotyped using a TaqMan assay (C_27465000_10) following the manufacturer instructions in an Applied Biosystems 7500 Real-Time PCR System (Life Technologies, formerly Applied Biosystems, Foster City, CA, USA) through allele-specific fluorescence signal discrimination. Following allele assignment for each patient, the allele and genotype frequencies were determined by simple counting. The adherence to Hardy-Weinberg equilibrium was assessed using the $\chi^{2}$ test. Polymorphism genotypes were considered as the primary predictors for the occurrence of adverse effects, and the remaining variables described above were considered as possible confounders. Therefore, they were included on a logistic regression model to assess whether the SNP had any influence

Genetics and Molecular Research 16 (1): gmr16019373 
on the outcome. In other words, the model assessed whether the SNP was associated with the development of AZT-related adverse effects when controlled for the patients' characteristics. The odds ratios (OR) and their respective 95\% confidence intervals (CI) were calculated.

All statistical analyses were performed using logistic regression through $\mathrm{R}$ software version 3.0.1 (R Core Team, 2013).

\section{RESULTS}

The sample consisted of $151(74.0 \%)$ women and $53(26 \%)$ men, with a median age of 34 years and an interquartile range $30-40$ on the ART start date. The majority of the patients reported being afro-descendants $(80.9 \%)$. The demographic characteristics of the patients and the adverse events developed during the first year of ART are summarized in Table 1.

Table 1. Demographic characteristics of the enrolled HIV patients receiving AZT +3 TC backbone regimens.

\begin{tabular}{l|c}
\hline Characteristic & Patients $(\mathrm{N}=204)$ \\
\hline Gender (\% women) & 74.0 \\
\hline Race (\% afro-descendant) & 80.9 \\
\hline Body mass (kg), median (IQR) & $60.2(53.9-68.2)$ \\
\hline Age (years old), median (IQR) & $34(30-40)$ \\
\hline Prevalence of adverse effects (\%) & 10.3 \\
\hline Anemia & 7.4 \\
\hline Dyslipidemia & 2.9 \\
\hline Fever & 25.5 \\
\hline Gastrointestinal toxicity & 10.3 \\
\hline Headache & 3.4 \\
\hline Hepatotoxicity & 23.0 \\
\hline Neurotoxicity & 16.2 \\
\hline Cutaneous rash & \\
\hline
\end{tabular}

$\mathrm{AZT}=$ zidovudine; $3 \mathrm{TC}=$ lamivudine $\mathrm{IQR}=$ interquartile range.

Some AZT-related adverse effects were reported in the first year of ART in these patients. For example, the two most common adverse effects were gastrointestinal toxicity (reported in $25.5 \%$ of the patients in the sample) and neurotoxicity $(23.0 \%)$, followed by cutaneous rash (16.2\%), anemia and headaches (both 10.3\%), dyslipidemia (7.4\%), hepatotoxicity $(3.4 \%)$ and fever $(2.9 \%)$. The prevalence of each of the reported AZT-related adverse effects is also presented in Table 1.

Genotyping was successful in 190 patients. The frequency of the variant genotype (C/A) was 7.4\%. The genotype counts were in accordance with the Hardy-Weinberg equilibrium. No A/A homozygous patients were found in our sample.

After the confounding factors (gender, age, and self-reported race) were included on a logistic regression model and adjusted, it was observed that the ITPA variant allele was associated with the occurrence of fever, but not with other adverse effects. We observed a higher frequency of ITPA variant genotype in patients reported with fever after AZT treatment when compared to patients with no fever reported (33.3 vs 6.5\%, respectively; OR $=7.17$, $95 \% \mathrm{CI}=1.19-43.15 ; \mathrm{P}=0.032)$. The allele and genotype counts as well as the genetic association test results with all the reported adverse effects (logistic regression modeling) are summarized in Table 2.

Genetics and Molecular Research 16 (1): gmr16019373 
Table 2. Genetic association tests through logistic regression modeling to determine the influence of ITPA rs1127354 (94 C>A, Pro32Thr) variant over the occurrence of zidovudine-related (AZT) adverse effects.

\begin{tabular}{|c|c|c|c|c|}
\hline Allele and genotype counts according to adverse effects & Cases N (\%) & Controls N (\%) & Logistic regression OR $(95 \% \mathrm{CI})$ & P value \\
\hline \multicolumn{5}{|l|}{ Anemia } \\
\hline A & $2(5.3)$ & $12(3.5)$ & & \\
\hline $\mathrm{C}$ & $36(94.7)$ & $330(96.5)$ & & \\
\hline $\mathrm{C} / \mathrm{A}$ & $2(10.5)$ & $12(7.0)$ & $1.56(0.32-7.56)$ & \multirow[t]{2}{*}{0.58} \\
\hline $\mathrm{C} / \mathrm{C}$ & $17(89.5)$ & $159(93.0)$ & Reference & \\
\hline \multicolumn{5}{|l|}{ Dyslipidemia } \\
\hline A & $0(0.0)$ & $14(4.0)$ & & \\
\hline $\mathrm{C}$ & $28(100.0)$ & $338(96.0)$ & & \\
\hline $\mathrm{C} / \mathrm{A}$ & $0(0.0)$ & $14(8.0)$ & Not calculated & \multirow[t]{2}{*}{0.99} \\
\hline $\mathrm{C} / \mathrm{C}$ & $14(100.0)$ & $162(92.0)$ & Reference & \\
\hline \multicolumn{5}{|l|}{ Fever } \\
\hline A & $2(16.7)$ & $12(3.3)$ & & \\
\hline $\mathrm{C}$ & $10(83.3)$ & $356(96.7)$ & & \\
\hline $\mathrm{C} / \mathrm{A}$ & $2(33.3)$ & $12(6.5)$ & $7.17(1.19-43.15)$ & \multirow[t]{2}{*}{0.032} \\
\hline $\mathrm{C} / \mathrm{C}$ & $4(66.7)$ & $172(93.5)$ & Reference & \\
\hline \multicolumn{5}{|l|}{ Gastrointestinal toxicity } \\
\hline A & $5(5.2)$ & $9(3.2)$ & & \\
\hline $\mathrm{C}$ & $91(94.8)$ & $275(96.8)$ & & \\
\hline $\mathrm{C} / \mathrm{A}$ & $5(10.4)$ & $9(6.3)$ & $1.72(0.55-5.41)$ & \multirow[t]{2}{*}{0.36} \\
\hline $\mathrm{C} / \mathrm{C}$ & $43(89.6)$ & $133(93.7)$ & Reference & \\
\hline \multicolumn{5}{|l|}{ Headache } \\
\hline A & $2(5.3)$ & $12(3.5)$ & & \\
\hline $\mathrm{C}$ & $36(94.7)$ & $330(96.5)$ & & \\
\hline $\mathrm{C} / \mathrm{A}$ & $2(10.5)$ & $12(7.0)$ & $1.56(0.32-7.56)$ & \multirow[t]{2}{*}{0.58} \\
\hline $\mathrm{C} / \mathrm{C}$ & $17(89.5)$ & $159(93.0)$ & Reference & \\
\hline \multicolumn{5}{|l|}{ Hepatotoxicity } \\
\hline A & $0(0.0)$ & $14(3.8)$ & & \\
\hline $\mathrm{C}$ & $14(100.0)$ & 352 (96.2) & & \\
\hline $\mathrm{C} / \mathrm{A}$ & $0(0.0)$ & $14(7.7)$ & Not calculated & \multirow[t]{2}{*}{0.99} \\
\hline $\mathrm{C} / \mathrm{C}$ & $7(100.0)$ & $169(92.3)$ & Reference & \\
\hline \multicolumn{5}{|l|}{ Neurotoxicity } \\
\hline $\mathrm{A}$ & $4(4.3)$ & $10(3.5)$ & & \\
\hline $\mathrm{C}$ & 88 (95.7) & $278(96.5)$ & & \\
\hline $\mathrm{C} / \mathrm{A}$ & $4(8.7)$ & $10(6.9)$ & $1.28(0.38-4.28)$ & \multirow[t]{2}{*}{0.69} \\
\hline $\mathrm{C} / \mathrm{C}$ & $42(91.3)$ & $134(93.1)$ & Reference & \\
\hline \multicolumn{5}{|l|}{ Cutaneous rash } \\
\hline A & $3(5.4)$ & $11(3.4)$ & & \\
\hline $\mathrm{C}$ & 53 (94.6) & $313(96.6)$ & & \\
\hline $\mathrm{C} / \mathrm{A}$ & $3(10.7)$ & $11(6.8)$ & $1.64(0.43-6.32)$ & \multirow{2}{*}{0.47} \\
\hline $\mathrm{C} / \mathrm{C}$ & $25(89.3)$ & $151(93.2)$ & Reference & \\
\hline
\end{tabular}

$\mathrm{OR}=$ odds ratio; $\mathrm{CI}=$ confidence interval.

\section{DISCUSSION}

The findings of this study led us to hypothesize a model to explain the mechanism by which ITPA modulates the occurrence of adverse effects during AZT therapy (Figure 1). To exert an antiretroviral effect, AZT must be phosphorylated to the AZT-triphosphate form (Peter and Gambertoglio, 1998). However, AZT-monophosphate is both a substrate and an inhibitor of thymidylate kinase (DTYMK), the enzyme that produces AZTdiphosphate (Furman et al., 1986). This inhibition would decrease the deoxythymidine triphosphate (dTTP) pool, since DTYMK is also involved in the phosphorylation of thymidine nucleotides. 


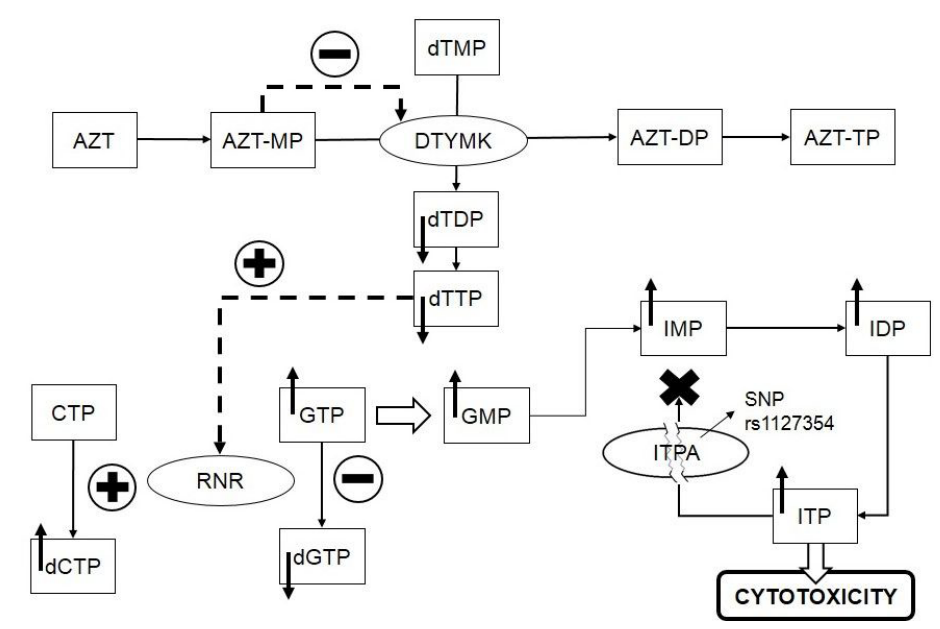

Figure 1. Relation between missense rs 1127354 variant (94 C $>$ A, Pro32Thr) on the inosine triphosphatase (ITPA) and zidovudine (AZT) adverse effects in an antimetabolite-like manner. AZT undergoes sequential steps of phosphorylation, generating AZT mono- (AZT-MP), di- (AZT-DP) and triphosphate (AZT-TP). AZT-MP is both a substrate and inhibitor of thymidylate kinase (DTYMK), interfering with phosphorylation of deoxythymidine monophosphate (dTMP) to diphosphate and triphosphate forms (dTDP and dTTP). The reduction of dTTP pools stimulates the ribonucleotide reductase (RNR) to shift from production of deoxyguanine triphosphate (dGTP) to deoxycytidine (dCTP) triphosphate instead. Consequently, guanosine nucleotide levels would rise, leading to higher synthesis of inosine monophosphate (IMP). Thus, inosine triphosphate levels (ITP) levels would also increase due to IMP phosphorylation. However, as the ITPA activity is compromised by the missense allele, ITP would not be converted to IMP, accumulating in cells, causing cytotoxicity, manifested as neutropenic fever. Some enzymes were ommitted in the depiction for simplicity.

The decrease in dTTP quantity would stimulate (by allosteric regulation) the ribonucleotide reductase enzyme to shift to the synthesis of deoxycytidine diphosphate (dCDP) instead of deoxyguanosine diphosphate (Frick et al., 1988). This would lead to two consequences, as previously reported in the cells exposed to prolonged dosages of AZT in vitro: 1) the dCDP and consequently dCTP pools would increase, finally leading to a higher uridine production via pyrimidine salvage pathway and 2) an imbalance of guanosine nucleotides, leading to GTP and GMP accumulation. Higher GMP quantities would result in higher levels of inosine monophosphate (IMP) via GMP reductase. The IMP pools are then converted to hypoxanthine (Agarwal et al., 1995).

Thus, AZT use would indirectly lead to increase in IMP levels in an antimetabolitelike manner, which may be converted to ITP. Since the ITPA activity is diminished owing to the rs 1127354 variant in some people, the ITP levels would accumulate leading to cytotoxicity (Stocco et al., 2010), which is manifested by neutropenia and fever (Stocco et al., 2009). The occurrence of fever could be explained by an undiagnosed mild infection during the course of ART treatment, a phenomenon already described during cancer chemotherapy (Bow, 2013). This new model for analyzing the mechanism by which AZT disturbs the nucleotide pools and how ITPA variants modulate the risk for AZT-related adverse effects needs further validation by in vitro and clinical studies.

Being retrospective, our study has many limitations. Therefore, we proposed a novel possible marker (ITPA variant genotype) in the multifactorial pharmacogenetic components that act together, to determine the onset of AZT adverse effects. 


\section{Conflicts of interest}

The authors declare no conflict of interest.

\section{ACKNOWLEDGMENTS}

facepe.br/).

Research supported by an APQ-0568-2.02/10 grant from FACEPE (http://www.

\section{REFERENCES}

Agarwal RP, He J, Bansal M and Gupta V (1995). Effect of long-term zidovudine exposure on salvage and de novo purine and pyrimidine nucleotide syntheses. Biochim. Biophys. Acta 1266: 223-228. http://dx.doi.org/10.1016/01674889(95)00018-N

Alves S, D'avila S, de Freitas MA, Freitas C, et al. (2012). Progress Report on the Brazilian Response to HIV/AIDS. Departamento de DST-AIDS e Hepatites Virais, Brasil, pp. 125. Available at [http://files.unaids.org/en/dataanalysis/ knowyourresponse/countryprogressreports/2012countries/UNGASS_2012_ingles_rev_08jun.pdf].

Bow EJ (2013). Infection in neutropenic patients with cancer. Crit. Care Clin. 29: 411-441. http://dx.doi.org/10.1016/j. ccc.2013.03.002

Coelho AV, Moura RR, Cavalcanti CA, Guimarães RL, et al. (2015). A rapid screening of ancestry for genetic association studies in an admixed population from Pernambuco, Brazil. Genet. Mol. Res. 14: 2876-2884. http://dx.doi. org/10.4238/2015.March.31.18

Cressey TR and Lallemant M (2007). Pharmacogenetics of antiretroviral drugs for the treatment of HIV-infected patients: an update. Infect. Genet. Evol. 7: 333-342.http://dx.doi.org/10.1016/i.meegid.2006.08.004

Fairman K and Matheral B (2000). Evaluating medication adherence: which measure is right for your program? Strategies 2: 4.

Fellay J, Thompson AJ, Ge D, Gumbs CE, et al. (2010). ITPA gene variants protect against anaemia in patients treated for chronic hepatitis C. Nature 464: 405-408.http://dx.doi.org/10.1038/nature08825

Frick LW, Nelson DJ, St Clair MH, Furman PA, et al. (1988). Effects of 3'-azido-3'-deoxythymidine on the deoxynucleotide triphosphate pools of cultured human cells. Biochem. Biophys. Res. Commun. 154: 124-129. http://dx.doi. org/10.1016/0006-291X(88)90659-6

Furman PA, Fyfe JA, St Clair MH, Weinhold K, et al. (1986). Phosphorylation of 3'-azido-3'-deoxythymidine and selective interaction of the 5'-triphosphate with human immunodeficiency virus reverse transcriptase. Proc. Natl. Acad. Sci. USA 83: 8333-8337. http://dx.doi.org/10.1073/pnas.83.21.8333

Jacobson MA, McGrath MS, Joseph P, Molaghan JB, et al. (1989). Zidovudine-induced fever. J. Acquir. Immune Defic. Syndr. 2: 382-388.

Maeda T, Sumi S, Ueta A, Ohkubo Y, et al. (2005). Genetic basis of inosine triphosphate pyrophosphohydrolase deficiency in the Japanese population. Mol. Genet. Metab. 85: 271-279. http://dx.doi.org/10.1016/j.ymgme.2005.03.011

Marinaki AM, Duley JA, Arenas M, Ansari A, et al. (2004). Mutation in the ITPA gene predicts intolerance to azathioprine. Nucleosides Nucleotides Nucleic Acids 23: 1393-1397. http://dx.doi.org/10.1081/NCN-200027639

Ministério da Saúde. (2010). Quais são os antirretrovirais? Secretária de Vigilância em Saúde. Departamento de DST, Aids e Hepatites Virais. Available at [http://www.aids.gov.br/pagina/quais-sao-os-antirretrovirais].

Mira JA, López-Cortés LF, Merino D, Arizcorreta-Yarza A, et al.; Grupo para el Estudio de las Hepatitis Viricas de la Sociedad Andaluza de Enfermedades Infecciosas (2007). Predictors of severe haematological toxicity secondary to pegylated interferon plus ribavirin treatment in HIV-HCV-coinfected patients. Antivir. Ther. (Lond.) 12: 1225-1235.

Montessori V, Press N, Harris M, Akagi L, et al. (2004). Adverse effects of antiretroviral therapy for HIV infection. CMAJ 170: 229-238.

Peter K and Gambertoglio JG (1998). Intracellular phosphorylation of zidovudine (ZDV) and other nucleoside reverse transcriptase inhibitors (RTI) used for human immunodeficiency virus (HIV) infection. Pharm. Res. 15: 819-825. http://dx.doi.org/10.1023/A:1011956011207

R Core Team (2013). R: A Language and Environment for Statistical Computing. R Foundation for Statistical Computing. Vienna, Austria. URL http://www.R-project.org/.

Said EA, Al-Yafei F, Zadjali F, Al-Balushi MS, et al. (2016). Frequency of TLR4 (1063A/G and 1363C/T) polymorphisms in healthy and HIV-infected Omani individuals and their relationship to viral load and T cell count. Genet. Mol. Res. 15: http://dx.doi.org/10.4238/gmr.15027671.

Genetics and Molecular Research 16 (1): gmr16019373 
Samie A, Moloro GT and Nangammbi TC (2014). Interleukin-7 receptor gene polymorphism at +1237 locus and its effect on susceptibility to opportunistic infections among HIV and AIDS patients in Limpopo Province, South Africa. Genet. Mol. Res. 13: 8757-8766. http://dx.doi.org/10.4238/2014.October.27.17

Stocco G, Cheok MH, Crews KR, Dervieux T, et al. (2009). Genetic polymorphism of inosine triphosphate pyrophosphatase is a determinant of mercaptopurine metabolism and toxicity during treatment for acute lymphoblastic leukemia. Clin. Pharmacol. Ther. 85: 164-172. http://dx.doi.org/10.1038/clpt.2008.154

Stocco G, Crews KR and Evans WE (2010). Genetic polymorphism of inosine-triphosphate-pyrophosphatase influences mercaptopurinemetabolism and toxicity during treatment of acutelymphoblasticleukemia individualized for thiopurineS-methyl-transferase status. Expert Opin. Drug Saf. 9: 23-37.http://dx.doi.org/10.1517/14740330903426151

Vella S, Giuliano M, Dally LG, Agresti MG, et al.; The Italian Zidovudine Evaluation Group (1994). Long-term follow-up of zidovudine therapy in asymptomatic HIV infection: results of a multicenter cohort study. J. Acquir. Immune Defic. Syndr. 7: 31-38.

von Ahsen N, Oellerich M and Armstrong VW (2008). Characterization of the inosine triphosphatase (ITPA) gene: haplotype structure, haplotype-phenotype correlation and promoter function. Ther. Drug Monit. 30: 16-22. http:// dx.doi.org/10.1097/FTD.0b013e318161a21a

Genetics and Molecular Research 16 (1): gmr16019373 